\section{Does wage bonus positively impact the economy?}

Productivity and wage bonus

\author{
Cuong Le-Van
}

Paris School of Economics, Paris, France and

TIMAS, Thang Long University, Hanoi, Vietnam, and

Nguyen To-The

VNU University of Economics and Business, Vietnam National University, Hanoi, Vietnam

\begin{abstract}
Purpose - Total factor productivity (TFP), for a country and for a firm as well, is a crucial element for economic growth by inducing high output. Actually, workers' effort is among the important factors that positively influence the TFP.

Design/methodology/approach - In this paper, the authors assume that the wage bonus enhances the worker's effort. Wage bonus is an incentive mechanism and plays a role in the TFP as is shown in a recent paper by Le Van and Pham (2021). The firm will maximize its profits. The supplies of capital and workers are exogenous. At equilibrium, the authors obtain that wage bonus has positive effects on output, labor productivity and price of the output.

Findings - The wage bonus system can make the optimal sequence of outputs grow without bounds. And if the optimal sequence converges to a steady state, this one can be characterized by higher output per capita than that in the steady state without the bonus.

Originality/value - In particular, the result show if, thanks to the wage bonus externality effect, the production may become of increasing returns and if the incentive mechanism is very strong, any optimal path of physical capitals will converge to infinity.
\end{abstract}

Keywords Productivity, TFP, Labor productivity, Wage bonus

\section{Introduction}

Productivity is a key concept in economics. It is crucial for economic growth since it induces high output of the firms. Let us recall that the total factor productivity (TFP) is the portion of growth, which is not explained by growth in inputs used in the production process. The TFP measures the efficiency with which factor inputs are combined and often used to proxy technological progress.

Estimating contribution to growth of different factors is not an easy task [1]. Looking back to history, Solow (1957) estimated that TFP growth accounted for $87.5 \%$ of growth in output per worker of the United States over the period 1909-1949 [2]. Similarly and more recently, Zhu (2012) estimated that the growth contribution of TFP growth is $78 \%$ of the growth in gross domestic product (GDP) per capita of China during 1978-2007.

In this paper, we propose to introduce an incentive mechanism by a wage bonus system. A firm announces a bonus which is proportional to real wage. The workers anticipate a real wage and improve their effort. At equilibrium, where anticipated wage equals equilibrium

\section{JEL Classification - E2, O4}

(C) Cuong Le-Van and Nguyen To-The. Published in Fulbright Review of Economics and Policy. Published by Emerald Publishing Limited. This article is published under the Creative Commons Attribution (CCBY 4.0) license. Anyone may reproduce, distribute, translate and create derivative works of this article (for both commercial and non-commercial purposes), subject to full attribution to the original publication and authors. The full terms of this license may be seen at http://creativecommons. org/licences/by/4.0/legalcode

The authors are grateful for very helpful comments and suggestions from the editor, and two anonymous reviewers are gratefully acknowledged. All remaining errors are the authors' own. 
FREP 1,1

wage, we obtain that the wage bonus system improves the output of firm, the real income per capita of the workers, the labor productivity and the competitiveness [3] of the firm as well. Moreover, the output per capita may increase without bound or converges to a steady state, which is larger than the one without a wage bonus system.

Our paper is in the stream of efficiency wages. Efficiency wage, which was introduced by Marshall (1890), would make employers pay different wages to workers who are of different efficiencies. Later, the use of the term is quite different and refers to the idea that higher wages may increase the productivity of the workers. For Leibenstein (1957), the wage-productivity relationship should be broken in two parts: (1) the relation between income and nutrition and (2) the relation between nutrition and productivity. Several theories try to explain why managers pay efficiency wages. For instance, since it is difficult to measure the quantity and the quality of the effort of the worker, and since this one may shirk by doing less work than agreed, the managers pay efficiency wages in order to increase or create the cost of job loss (see, for instance, Shapiro \& Stiglitz, 1984). In Solow (1979), wage enters the short-run production function. A firm can minimize the cost by letting its wage offer unchanged if wage enters the production function in a labor augmenting way. Solow (1979) explains why wage may be sticky. Combining efficiency wage theory and public service motivation, Taylor \& Taylor (2011) build a model to examine empirically the relationship between wages and public service motivation for 15 countries.

The remaining of the study is organized as follows. In Section 2, we recall the definition of TFP and give the several factors constituting the TFP. In Section 3, we define the wage bonus system. The economy is set in Section 4. The results are given in Section 5. In Section 6, we set an optimal growth model where, in presence of wage bonus system, the sequence of optimal outputs per capita may converge to infinity or converge to a steady state, which is larger than the one without a wage bonus system. In particular, we show if, thanks to the wage bonus externality effect, the production may become of increasing returns and if the incentive mechanism is very strong, any optimal path of physical capitals will converge to infinity. All the results are summarized in Section 7 which concludes.

\section{Total factor productivity and economic growth}

This study employed Solow (1957) to clarify the relationship between TFP and economic growth. In this paper, Solow used the data of the US economy of the 50 beginning years of the 20 th century and ran a regression.

$$
\Delta \ln \left(Y_{t}\right)=B+\alpha \Delta \ln \left(K_{t}\right)+\beta \Delta \ln \left(N_{t}\right),
$$

where $Y_{t}, K_{t}$ and $N_{t}$ are, respectively, the GDP, physical capital and number of workers. Solow (1957) found that TFP growth accounted for $87.5 \%$ of growth in output per worker over that period.

We can see that this regression is derived from a production function (Cobb-Douglas function).

$$
Y_{t}=A_{t} K_{t}^{\alpha} N_{t}^{\beta}
$$

Obviously, $B=\Delta \ln \left(A_{t}\right)$ in the regression [4]. $B$ is called Solow residual while $A_{t}$ is called technical progress or TFP. TFP is the portion of growth in output not explained by growth in traditionally measured inputs of labor and capital used in production. TFP is measured as the ratio of aggregate output (e.g. GDP) to aggregate inputs (here, when $\beta=1-\alpha$, the quantity $K^{\alpha} N^{\beta}$ represents aggregate inputs as a weighted product of inputs $K$ and $N$ ). The rate of TFP growth is calculated by subtracting average growth rates of labor and capital inputs from the growth rate of output. 
Furthermore, Le Van \& Pham (2021) consider Harrod, Solow and Ramsey models to show that, for a closed economy, its growth depends crucially on the TFP. If the TFP is high then the economy takes off and grows without bound. If the TFP is low, the economy collapses [5].

They show that the TFP is not a blackbox. By referring to the concepts (knowledge, human capital and management) introduced by Romer (1986), Lucas (1988) and Bloom, Eifert, Mahajan, McKenzie \& Roberts (2013), they propose a production function $Y=A K^{\alpha} N^{\beta}$ where the TFP is $A \equiv\left[a m \zeta^{\alpha}(\theta h)^{\beta}\right]$, where $a$ is a normalization constant, $m$ is an indicator of the management quality, $h$ is the human capital, $\zeta$ is the quality of the technology of the physical capital and $\theta$ is the workers effort. We assume $\theta$ depends positively on a bonus denoted by $b$ (incentive mechanism). To summarize, we have the following production function.

$$
Y=A k^{\alpha} N^{\beta}
$$

$$
\text { with the TFP is } A=\left[\operatorname{am} \zeta^{\alpha}(\theta h)^{\beta}\right]
$$

\section{Wage bonus as an incentive mechanism}

We define the wage bonus $b$ by $b=\mu \omega$, where $\mu \geqslant 0$ and $\omega$ is real wage [6]. The real earned income of a worker, $I$, will now be $I=\omega+b=(1+\mu) \omega$. For simplicity, we write $\theta(b)^{\beta}=\varepsilon(\mu \omega)$. Since we focus on the effect of real wage bonus, we suppose, for convenience, that $1=\left[a m \zeta^{\alpha} h^{\beta}\right]$. The production function (Eqn 3) now becomes

$$
Y=\varepsilon(\mu \omega) K^{\alpha} N^{1-\alpha}
$$

\section{Assumption:}

We assume the function $\varepsilon$ has the form

$$
\varepsilon(\mu \omega)=1+\lambda \xi(\mu \omega)
$$

The function $\xi$ will be called the incentive mechanism function. It is strictly increasing, $\xi(0)=0$, strictly concave, differentiable, $\lim _{x \rightarrow+\infty} \frac{\xi(x)}{x}=0$. The parameter $\lambda>0$ measures the intensity of the incentive mechanism.

\section{Comments on assumption}

(1) Assume $\xi(0)=0$ means no bonus implies no incentive mechanism. The effort equals 1 in this case.

(2) The assumption $\lim _{x \rightarrow+\infty} \frac{\xi(x)}{x}=0$ means the effort cannot expand widely. In particular, when there is a maximal value for the workers effort $(\xi(+\infty)<+\infty)$, this assumption is satisfied.

\section{The economy}

In our economy, there exists a firm which produces a good by using $k$ machines and $N$ workers. The production technology is given by

$$
Y=\varepsilon\left(\mu \omega^{e}\right) K^{\alpha} N^{1-\alpha}=\left[1+\lambda \xi\left(\mu \omega^{e}\right)\right] K^{\alpha} N^{1-\alpha},
$$

where $\omega^{e}$ is the real wage anticipated by the workers. 
FREP

1,1

The firm will maximize its profit

$$
\pi=\varepsilon\left(\mu \omega^{e}\right) K^{\alpha} N^{1-\alpha}-\left(\omega+\mu \omega^{e}\right) N-r K,
$$

where $r$ is real capital cost. In this economy, there is an exogenous supply of workers $\mathcal{N}$ and an exogenous supply of physical capital $\mathcal{K}$. Given $\omega, \omega^{e}, r$, the demands of firm for capital $K^{d}\left(\omega, \omega^{e}, r\right)$ and for workers $N^{d}\left(\omega, \omega^{e}, r\right)$ are obtained by maximizing its profit.

\subsection{Equilibrium}

Equilibrium real wages, $\omega^{*}$ and real capital cost $r^{*}$ are characterized by,

(1) $\omega^{e}=\omega^{*}$.

(2) $N^{d}\left(\omega^{*}, \omega^{e}, r *\right)=\mathcal{N}$

(3) $K^{d}\left(\omega^{*}, \omega^{e}, r^{*}\right)=\mathcal{K}$

\section{The results}

The demands for capital and for workers satisfy.

$$
\begin{aligned}
& \frac{\varepsilon\left(\mu \omega^{e}\right) \alpha}{r}=\left(\frac{K^{d}}{N^{d}}\right)^{1-\alpha} \\
& \frac{\varepsilon\left(\mu \omega^{e}\right)(1-\alpha)}{\omega+\mu \omega^{e}}=\left(\frac{N^{d}}{K^{d}}\right)^{\alpha}
\end{aligned}
$$

Therefore, the equilibrium real wages and real capital cost solve the system.

$$
\begin{gathered}
\frac{\varepsilon\left(\mu \omega^{*}\right) \alpha}{r^{*}}=\left(\frac{\mathcal{K}}{\mathcal{N}}\right)^{1-\alpha} \\
\frac{\varepsilon\left(\mu \omega^{*}\right)(1-\alpha)}{\omega^{*}(1+\mu)}=\left(\frac{\mathcal{N}}{\mathcal{K}}\right)^{\alpha}
\end{gathered}
$$

To prove that Eqn (8) has a unique solution $\omega^{*}>0$, we require the following result.

Claim 1. The function, for $x \geqslant 0, \psi(x)=\frac{\varepsilon(x)}{x}$ is strictly decreasing. Moreover, $\psi(0)=$ $+\infty, \psi(+\infty)=0$.

Proof. We have,

$$
\begin{aligned}
\psi^{\prime}(x) & =\frac{\varepsilon^{\prime}(x)}{x}-\frac{\varepsilon(x)}{x^{2}} \\
& =\frac{\lambda \xi^{\prime}(x)}{x}-\frac{1+\lambda \xi(x)}{x^{2}} \\
& =\frac{\lambda\left[x \xi^{\prime}(x)-\xi(x)\right]-1}{x^{2}}
\end{aligned}
$$


Since $\xi$ is strictly concave, differentiable, we have $\xi(x)-\xi(0)>x \xi^{\prime}(x)$, and since $\xi(0)=0$, we have $x \xi^{\prime}(x)-\xi(x)<0$. Hence, $\psi^{\prime}(x)<0, \forall x>0$. We have $\psi(x)>\frac{1}{x}$ for all $x>0$. Hence, $\psi(x)$ $\rightarrow+\infty$ when $x \rightarrow 0$. Since $\psi(x)=\frac{1+\lambda \xi(x)}{x}$, we have $\psi(x) \rightarrow 0$ when $x \rightarrow+\infty$.

Therefore, Eqn (8) gives a unique value for the equilibrium real wage $\omega^{*}$; by consequence, Eqn (7) gives a unique value for the equilibrium real capital cost $r^{*}$.

Let $\tilde{\omega}$ be the equilibrium real wage and $\tilde{r}$ be the equilibrium real capital cost when there is no bonus, i.e. $\mu=0$. We obtain,

$$
\begin{gathered}
\frac{\alpha}{\tilde{r}}=\left(\frac{\mathcal{K}}{\mathcal{N}}\right)^{1-\alpha} \\
\frac{(1-\alpha)}{\tilde{\omega}}=\left(\frac{\mathcal{N}}{\mathcal{K}}\right)^{\alpha}
\end{gathered}
$$

It follows from Eqns (8) and (10) that

$$
\frac{(1+\mu) \omega^{*}}{\tilde{\omega}}=\varepsilon\left(\mu \omega^{*}\right)>1
$$

In other words, the real income per capita, with bonus, $(1+\mu) \omega^{*}$, is higher than the real income per capita without bonus $\tilde{\omega}$.

Also, it follows from Eqns (7) and (9) that $r^{*}>\tilde{r}$. To interpret this result, let $q$ denote the price of the physical capital. In this case, $\tilde{r}=\frac{q}{\tilde{p}}$ and $r^{*}=\frac{q}{p^{*}}$, where $\tilde{p}$ and $p^{*}$ are, respectively, the prices of the output when there are no wage bonus. Suppose $q$ is exogenous, we conclude that the price of the output is lower when there is wage bonus.

The output, in presence of the wage bonus, $Y^{*}=\varepsilon\left(\mu \omega^{*}\right) \mathcal{K}^{\alpha} \mathcal{N}^{1-\alpha}$ is larger than $\mathcal{K}^{\alpha} \mathcal{N}^{1-\alpha}$ which is the output $\widetilde{Y}$, when the firm does not propose wage bonus.

Finally, we observe that the labor productivity $\pi_{L}^{*}$ with wage bonus is higher than the labor productivity $\tilde{\pi}_{L}$ without wage bonus. Indeed,

$$
\pi_{L}^{*}=\varepsilon\left(\mu \omega^{*}\right)\left(\frac{\mathcal{K}}{\mathcal{N}}\right)^{\alpha}>\tilde{\pi}_{L}=\left(\frac{\mathcal{K}}{\mathcal{N}}\right)^{\alpha}
$$

Remark 1. We mention that with bonus, if the real income per capita $(1+\mu) \omega^{*}$ is higher than the one without bonus $\tilde{\omega}$, we do not necessarily have that $\omega^{*}>\tilde{\omega}$. The following example is a counter example.

Suppose $\xi(x)=x^{\gamma}, 0<\gamma<1$. In this case, we get

$$
\frac{1+\lambda \mu^{\gamma} \omega^{* \gamma}}{(1+\mu) \omega^{*}}=\frac{1}{\tilde{\omega}}
$$

It is easy to check that $\omega^{*}>\tilde{\omega} \Leftrightarrow \lambda>\frac{1}{\tilde{\omega}^{\gamma}} \mu^{1-\gamma}$. That means $\omega^{*}>\tilde{\omega}$ if, and only if, the intensity parameter of the incentive mechanism, $\lambda$ is high. If $\lambda<\frac{1}{\tilde{\omega}^{\gamma}} \mu^{1-\gamma}$ then $\omega^{*}<\tilde{\omega}$.

Remark 2. We want to show that, at equilibrium, the bonus $\mu \omega^{*}$ is bounded above. Indeed, on the one hand, we have the relations.

$$
\frac{\varepsilon\left(\mu \omega^{*}\right)}{\mu \omega^{*}}>\frac{\varepsilon\left(\mu \omega^{*}\right)}{(1+\mu) \omega^{*}}=\frac{1}{\tilde{\omega}}
$$


FREP

1,1

which imply

$$
1+\lambda \xi\left(\mu \omega^{*}\right)>\frac{\mu \omega^{*}}{\tilde{\omega}}
$$

and, on the other hand, the function $1+\lambda \xi(x)$ has a unique $\bar{x}$, which depends on $\lambda, \tilde{\omega}$, such that

Hence, $\mu \omega^{*}<\bar{x}(\lambda, \tilde{\omega})$.

$$
\begin{aligned}
& 1+\lambda \xi(\bar{x})=\frac{\bar{x}}{\tilde{\omega}} \\
& 1+\lambda \xi(x)>\frac{x}{\tilde{\omega}} \text { if } x<\bar{x} \\
& 1+\lambda \xi(x)<\frac{x}{\tilde{\omega}} \text { if } x>\bar{x}
\end{aligned}
$$

\section{Wage bonus and economic growth}

In this section, we consider an infinite horizon closed economy where there exists a social planner who represents $\mathcal{N}$ identical consumers. The consumers are also firms and workers. They provide physical capital to the firm by using their savings. The supply of labor is exogenous and constant over time. It equals $\mathcal{N}$. The social planner seeks an economic growth path of consumptions $\left(\mathcal{N} c_{t}^{*}\right)_{t \geqslant 0}$ and physical capitals $\left(K_{t+1}^{*}\right)_{t \geqslant 0}$ such that, along this growth path,

(1) firm uses the wage bonus system described in the sections above.

(2) firm maximizes the profit at each period.

(3) There is full employment of labor.

(4) At each period, the saving of the consumers is used to invest in physical capital which they sell to the firm.

(5) The social planner maximizes the intertemporal utilities of the consumers under the constraints that the consumptions and the savings equal their incomes. These ones are composed of the profit of the firm, the value of the physical capital they sell to the firm and their earned income (wage plus bonus).

(6) The income at period 0 of the consumers is $K_{0}^{\alpha} \mathcal{N}^{1-\alpha}$.

Let $S_{t}^{*}$ denote the saving of the consumers. If $r_{t}^{*}, \omega_{t}^{*}$ denote the capital price and the wage at date $t$, since the production function is of constant returns to scale, the profit is null, and the constraint of the consumers, at any period $t \geqslant 1$ writes

$$
\mathcal{N} c_{t}^{*}+S_{t}^{*}=r_{t}^{*} K_{t}^{*}+(1+\mu) \omega_{t}^{*} \mathcal{N}
$$

and

$$
K_{t+1}^{*}=S_{t}^{*}
$$

Since [7] the profit is null, we have $r_{t}^{*} K_{t}^{*}+(1+\mu) \omega_{t}^{*} \mathcal{N}=Y_{t}^{*}$ where $Y_{t}^{*}$ is the output of firm which equals $\varepsilon\left(\mu \omega_{t}^{*}\right) K_{t}^{* \alpha} \mathcal{N}^{1-\alpha}$ [8].

Since the firm maximizes its profit at each period, $\omega_{t}^{*}$ is obtained (see Section 5)

$$
\frac{\varepsilon\left(\mu \omega_{t}^{*}\right)(1-\alpha)}{\omega_{t}^{*}(1+\mu)}=\left(\frac{\mathcal{N}}{K_{t}^{*}}\right)^{\alpha}
$$


The constraints of the consumers are rewritten as follows:

$$
\begin{gathered}
\mathcal{N} c_{0}^{*}+K_{1}^{*}=K_{0}^{\alpha} \mathcal{N}^{1-\alpha} \\
\text { for } t>0, \quad \mathcal{N} c_{t}^{*}+K_{t+1}^{*}=\varepsilon\left(\omega_{t}^{*}\left(\frac{K_{t}^{*}}{\mathcal{N}}\right)\right) K_{t}^{* \alpha} \mathcal{N}^{1-\alpha}
\end{gathered}
$$

Productivity and wage bonus

In the following, we will consider the capital per capita, the output per capita and the consumption per capita and define

$$
k_{t}^{*}=\frac{K_{t}^{*}}{\mathcal{N}}, y_{t}^{*}=\frac{Y_{t}^{*}}{\mathcal{N}}
$$

and $k_{0}=\frac{K_{0}}{\mathcal{N}^{*}}$

We then obtain the constraint of each consumer

$$
\begin{array}{ll} 
& c_{0}^{*}+k_{1}^{*}=k_{0}^{\alpha} \\
\text { for } t>0, & c_{t}^{*}+k_{t+1}^{*}=\varepsilon\left(\omega_{t}^{*}\left(k_{t}^{*}\right)\right) k_{t}^{* \alpha}
\end{array}
$$

We assume that each consumer has the same intertemporal utility function $\ln \left(c_{0}\right)+\beta \ln \left(c_{1}\right)+\cdots+\beta^{t} \ln \left(c_{t}\right)+\ldots$

The social planner now solves for each consumer the optimal growth model

$$
\begin{array}{ll} 
& \max _{\left\{\left(c_{t}, k_{t+1}\right), t \geqslant 0\right\}} \sum_{t=0}^{+\infty} \beta^{t} \ln \left(c_{t}\right), \beta \in(0,1) \\
& c_{0}+k_{1}=k_{0}^{\alpha} \\
\text { for } t>0, & c_{t}+k_{t+1}=\varepsilon\left(\omega_{t}^{*}\left(k_{t}\right)\right) k_{t}^{\alpha} \equiv F\left(k_{t}\right)
\end{array}
$$

Observe that the left hand side (LHS) of Eqn (12) is a decreasing function in $\omega_{t}^{*}$ and the right hand side (RHS) of Eqn (12) is also a decreasing function in $K_{t}$. Hence, $\omega_{t}^{*}$ is an increasing function in $K_{t}$. In particular, if $K_{t} \rightarrow 0$ then $\omega_{t}^{*} \rightarrow 0$.

Since the function $F$ is increasing, the optimal sequence of physical capitals $\left(k_{t}^{*}\right)_{t \geqslant 1}$ is monotonic (see Amir, 1996).

We will show that the optimal path $\left(k_{t}^{*}\right)_{t}$ cannot converge to zero by using the Euler equation associated with this optimal growth model. The Euler equation writes, with $\left(c_{t}^{*}\right)_{t}$ optimal consumption path.

For all $t$ :

$$
\begin{aligned}
\frac{c_{t+1}^{*}}{c_{t}^{*}} & =\beta\left[\mu \varepsilon^{\prime}\left(\mu \omega^{*}\left(k_{t+1}^{*}\right)\right) \omega^{*^{\prime}}\left(k_{t+1}^{*}\right) k_{t+1}^{* \alpha}+\alpha \varepsilon\left(\mu \omega^{*}\left(k_{t+1}^{*}\right)\right)\left(k_{t+1}^{*}\right)^{\alpha-1}\right] \\
& >\beta\left[\alpha \varepsilon\left(\mu \omega^{*}\left(k_{t+1}^{*}\right)\right)\left(k_{t+1}^{*}\right)^{\alpha-1}\right]>\beta \alpha\left(k_{t+1}^{*}\right)^{\alpha-1}
\end{aligned}
$$

since $\varepsilon()>$.1 .

If the sequence $\left(k_{t}^{*}\right)_{t}$ converges to zero, then the sequence $\left(\frac{c_{t+1}^{*}}{c_{t}^{*}}\right)_{t}$ will converge to infinity, since $\left(k_{t+1}^{*}\right)^{\alpha-1} \rightarrow+\infty$. That implies there exists $T$ such that for any $t>T$ we have $c_{t+1}^{*}>c_{t}^{*}>\ldots>c_{T}^{*}>0$. 
FREP

1,1

However, the budget constraint

$$
c_{t}^{*}=F\left(k_{t}^{*}\right)-k_{t+1}^{*}
$$

implies that $c_{t}^{*}$ converges to zero, since $F\left(k_{t}^{*}\right) \rightarrow 0$ and $k_{t+1}^{*} \rightarrow 0$ : we get a contradiction.

Therefore, the sequence $\left(k_{t}^{*}\right)_{t}$ and the sequence of optimal outputs per capita $y_{t}^{*}=F\left(k_{t}^{*}\right)$ either are increasing and may converge to infinity, i.e. grow without bound or converge to steady states $\widehat{y}=F(\widehat{k})$ with $\widehat{k}=\lim _{t \rightarrow+\infty} k_{t}^{*}$.

Suppose that the optimal sequence $\left(k_{t}^{*}\right)_{t}$ converge to a steady state $\widehat{k}$. Then the optimal consumptions $c_{t}^{*}$ converge to a steady state $\widehat{c}>0$.

From Euler Eqn (14), we have

$$
\begin{aligned}
1 & =\beta\left[\mu \varepsilon^{\prime}\left(\mu \omega^{*}(\widehat{k})\right) \omega^{*^{\prime}}(\widehat{k}) \widehat{k}^{\alpha}+\alpha \varepsilon\left(\mu \omega^{*}(\widehat{k})\right) \widehat{k}^{\alpha-1}\right] \\
& >\beta \alpha \varepsilon\left(\mu \omega^{*}(\widehat{k})\right) \widehat{k}^{\alpha-1}
\end{aligned}
$$

We now compare with the case where $\mu=0$ (no wage bonus). In this case, from Le Van $\&$ Dana (2003), the optimal sequence $\tilde{k}_{t}$ will converge to a steady state $\bar{k}$ which satisfy

$$
1=\beta \alpha \bar{k}^{\alpha-1}
$$

We see, from Eqn (15), that

$$
\bar{k}^{\alpha-1}>\varepsilon\left(\mu \omega^{*}(\widehat{k})\right) \widehat{k}^{\alpha-1} \Leftrightarrow \widehat{k}>\varepsilon\left(\mu \omega^{*}(\widehat{k})\right)^{\frac{1}{1-\alpha}} \bar{k}>\bar{k}
$$

and for the output per capita

$$
\widehat{y}=\varepsilon\left(\mu \omega^{*}(\widehat{k})\right) \widehat{k}^{\alpha}>\bar{y}=\bar{k}^{\alpha}
$$

At the steady state, the country is better off with a wage bonus system than without a bonus system. We can summarize these results in the following proposition:

Proposition 1. An optimal path $\left(k_{t}^{*}\right)_{t \geqslant 1}$ either converges to infinity or converges to a steady state $\widehat{k}$, which is larger the steady state $\bar{k}=(\beta \alpha)^{\frac{1}{1-\alpha}}$ corresponding to the no wage bonus system.

Recall that $\varepsilon(\mu \omega)=1+\lambda \xi(\mu \omega)$. Under some additional assumptions, any optimal path $\left(k_{t}^{*}\right)_{t \geqslant 1}$ converges to infinity.

Proposition 2. Assume $\xi(x)=x^{\gamma}, \gamma \in(0,1)$ and $\alpha+\gamma>1$. Then there exists $\bar{\lambda}$ such that for any $\lambda>\bar{\lambda}$, any optimal path $\left(k_{t}^{*}\right)_{t \geqslant 1}$ converges to infinity.

Proof. Suppose an optimal path $\left(k_{t}^{*}\right)_{t}$ converges to a steady state $\widehat{k}$. Then it must satisfy (15). But it also satisfies (12), i.e.

$$
\frac{\varepsilon\left(\mu \omega^{*}(\widehat{k})\right)(1-\alpha)}{\omega^{*}(\widehat{k})(1+\mu)}=\left(\frac{1}{\widehat{k}}\right)^{\alpha}
$$

Equivalently,

$$
\frac{1+\lambda \mu^{\gamma} \omega^{*}(\widehat{k})^{\gamma}}{\omega^{*}(\widehat{k})} \times \frac{(1-\alpha)}{(1+\mu)}=\left(\frac{1}{\widehat{k}}\right)^{\alpha}
$$


This implies

$$
\begin{aligned}
& \lambda \mu^{\gamma} \omega^{*}(\widehat{k})^{\gamma-1} \times \frac{(1-\alpha)}{(1+\mu)}<\left(\frac{1}{\widehat{k}}\right)^{\alpha} \\
\Leftrightarrow \quad & \lambda \mu^{\gamma} \frac{(1-\alpha) \widehat{k}^{\alpha}<\omega^{*}(\widehat{k})^{1-\gamma}}{(1+\mu)} \\
\Leftrightarrow \quad & \omega^{*}(\widehat{k})>\left(\lambda \mu^{\gamma} \frac{(1-\alpha)}{(1+\mu)}\right)^{\frac{1}{1-\gamma}} \widehat{k}^{\frac{\alpha}{1-\gamma}}
\end{aligned}
$$

Observe that from Eqn (15), one gets

$$
1>\beta \alpha \lambda \mu^{\gamma} \omega^{*}(\widehat{k})^{\gamma} \widehat{k}^{\alpha-1}
$$

Combine Eqns (20) and (19) to obtain

$$
\begin{aligned}
1 & >\beta \alpha \lambda \mu^{\gamma}\left(\frac{(1-\alpha)}{(1+\mu)} \lambda \mu^{\gamma}\right)^{\frac{\gamma}{1-\gamma}} \widehat{k}^{\frac{\alpha+\gamma-1}{1-\gamma}} \\
\Leftrightarrow \quad 1 & >\left[\beta \alpha \mu^{\gamma}\left(\frac{(1-\alpha)}{(1+\mu)} \mu^{\gamma}\right)^{\frac{\gamma}{1-\gamma}}\right] \lambda^{\frac{1}{1-\gamma} \widehat{k}^{\frac{\alpha+\gamma-1}{1-\gamma}}}
\end{aligned}
$$

Let $\nu \equiv\left[\beta \alpha \mu^{\gamma}\left(\frac{(1-\alpha)}{(1+\mu)} \mu^{\gamma}\right)^{\frac{\gamma}{1-\gamma}}\right]$. Then Eqn (21) rewrites as

$$
\begin{aligned}
& 1>\nu \lambda^{\frac{1}{1-\gamma}} \widehat{k}^{\frac{\alpha+\gamma-1}{1-\gamma}} \\
& \Leftrightarrow \quad \widehat{k}<\nu^{\frac{\gamma-1}{\alpha+\gamma-1}} \lambda^{\frac{1}{\alpha+\gamma-1}}
\end{aligned}
$$

We see from Eqn (22) that, since $\alpha+\gamma>1$, if $\lambda$ goes to infinity, then $\widehat{k}$ goes to zero. Hence, there exists $\bar{\lambda}$ such that, if $\lambda>\bar{\lambda}$ then $\widehat{k}<\bar{k}\left(\bar{k}=(\beta \alpha)^{\frac{1}{1-\alpha}}\right.$, in Proposition 1. That contradicts the statement in Proposition 1. Recall that any optimal path $\left(k_{t}^{*}\right)_{t}$ is monotonic and cannot converge to zero. Hence, any optimal $\left(k_{t}^{*}\right)_{t}$ converges to infinity.

The interpretation of this result is as follows: if the production function becomes of increasing returns $(\alpha+\gamma>1)$ and if the incentive parameter $\lambda$ is high, then we have unbounded growth.

Remark 3. Along the optimal path, at each period t, the capital price $r_{t}^{*}$ is determined by the equation (see Section 5)

$$
\frac{\varepsilon\left(\mu \omega_{t}^{*}\right) \alpha}{r_{t}^{*}}=\left(\frac{\mathcal{N} k_{t}^{*}}{\mathcal{N}}\right)^{1-\alpha}=k_{t}^{* 1-\alpha}
$$

while the wage $\omega_{t}^{*}$ is given by

$$
\frac{\varepsilon\left(\mu \omega_{t}^{*}\right)(1-\alpha)}{\omega_{t}^{*}(1+\mu)}=\left(\frac{\mathcal{N}}{\mathcal{N} k_{t}^{*}}\right)^{\alpha}=\frac{1}{k_{t}^{* \alpha}}
$$




\section{FREP 1,1}

\section{Conclusion}

In our study, we obtain the following results,

(1) The real income per capita of the workers is higher with the wage bonus system;

(2) The output is also larger when the firm uses wage bonus as an incentive mechanism;

(3) If the price of the physical capital is exogenous, then the price of the output is lower in presence of the wage bonus system. This will be beneficial for the consumers and also for firm which becomes more competitive;

(4) Labor productivity improves with the wage bonus system;

(5) We set up an optimal growth model where in presence of the bonus system the optimal outputs per capita sequence may converge to infinity or converges to a steady state, which is higher than the one corresponding to the case without the wage bonus system and

(6) Moreover, if the production function becomes of increasing returns and if the incentive mechanism is high, then we have unbounded growth.

\section{Notes}

1. See Hulten (2009) for a great treatment of growth accounting.

2. Solow was awarded the Nobel Memorial Prize in Economic Sciences in 1987 for his contributions to the theory of economic growth. The paper Solow (1957) is an important part of these contributions.

3. We say that a firm becomes more competitive if its output price diminishes

4. The TFP $A_{t}$ has constant rate of growth.

5. The readers can also refer to Le Van \& Dana (2003) for more details.

6. In this paper, the bonus depends on wage. The wage bonus improves the economy in different ways. One can ask whether an "optimal" wage bonus exists or not. Consider the well-known efficiency wage which consists to pay a salary higher than the one which clears the labor market. An optimal efficiency wage is achieved when the marginal costs of an increase in wage equals the marginal benefit of the improved productivity. In this paper, we show (see (11)) that, at equilibrium, the earned income, i.e. salary plus bonus, of the worker is larger than the salary she/he gets, at equilibrium, when there is no incentive. That is due to an increase of the TFP. In some sense, the bonus corresponds to the idea of optimality.

7. We suppose the capital depreciation rate equals 1 .

8. The function $\varepsilon$ is as in the previous sections.

\section{References}

Amir, R. (1996). Sensitivity analysis of multisector optimal economic dynamics. Journal of Mathematical Economics, 25(1), 123-141.

Bloom, N., Eifert, B., Mahajan, A., McKenzie, D., \& Roberts, J. (2013). Does management matter? Evidence from Inida, Quarterly Journal of Economics, 128(1), 1-51.

Hulten, C. R. (2009). Dynamic Programming in Economics, Springer Science \& Business Media.

Le Van, C., \& Dana, R. A. (2003), Dynamic Programming in Economics, Kluwer Academic Publishers. Le Van, C., \& Pham, N. S. (2021), “Why does productivity matter?”, Working Paper (halshs-03139392).

Leibenstein, H. (1957). The theory of underemployment in backward economies. The Journal of Political Economy, 65(2), 91-103. 
Lucas, R. E. (1988). On the mechanics of economic development. Journal of Monetary Economics, 22(1), $3-42$.

Marshall, A. (1890), Principles of Economics (8th ed.). Macmillan, London.

Romer, P. M. (1986). Increasing returns and long-run growth. Journal of Political Economy, 94(5), 1002-1037.

Shapiro, C., \& Stiglitz, J. E. (1984). Unemployment as a worker discipline device. The American Economic Review, 74(3), 433-444.

Solow, R. (1957). Technical change and the aggregate production function. Review of Economics and Statistics, 39(3), 312-320.

Solow, R. (1979). Another possible source of wage stickiness. Journal of Macroeconomics, 1(1), 79-82.

Taylor, J., \& Taylor, R. (2011). Working hard for more money or working hard to make a difference? efficiency wages, public service motivation and effort. Review of Public Personnel Administration, 31(1), 67-86.

Zhu, X. (2012). Understanding China's growth: Past, present, and future. The Journal of Economic

Perspectives, 26(4), 103-124.

\section{Corresponding author}

Nguyen To-The can be contacted at: tothenguyen@gmail.com
Productivity and wage bonus

For instructions on how to order reprints of this article, please visit our website: 